\title{
How students in the Kingdom of Saudi Arabia are coping with COVID-19 pandemic
}

\author{
Heba Bakr Khoshaim, ${ }^{1}$ Areej Al-Sukayt, ${ }^{2}$ Karuthan Chinna, ${ }^{3}$ Mohammad Nurunnabi, ${ }^{2}$ \\ Sheela Sundarasen, ${ }^{2}$ Kamilah Kamaludin, ${ }^{2}$ Gul Mohammad Baloch, ${ }^{3}$ Syed Far Abid Hossain ${ }^{4}$ \\ ${ }^{1}$ Deanship of Educational Services, Prince Sultan University, Riyadh, Saudi Arabia; ${ }^{2}$ Department of Accounting, \\ Prince Sultan University, Riyadh, Saudi Arabia; ${ }^{3}$ School of Medicine, Faculty of Health and Medical Sciences, \\ Taylor's University, Jalan Taylors, Subang Jaya, Selangor, Malaysia; ${ }^{4}$ College of Business Administration, \\ IUBAT-International University of Business Agriculture and Technology, Dhaka, Bangladesh
}

\begin{abstract}
The novel coronavirus is the worst pandemic of this century. Unfortunately, there is no clear solution for how to cope with such an epidemic. This study examines the coping strategies used by university students in the Kingdom of Saudi Arabia. From March to May 2020, a questionnaire was administered and completed by 400 students. This study used the Zung Self-rating Anxiety Scale (SAS) to examine the respondents' level of anxiety. The results indicate that $35 \%$ of students experienced some levels of anxiety. Moreover, there was a moderate use of four types of coping strategies: Seek social support, acceptance, mental disengagement, and humanitarian. These findings can guide policymakers on the importance of developing practical guidelines to handle such lethal diseases. Moreover, the results inform the Saudi community what strategies were used to cope so far with the pandemic. Future research is expected to address the validity and appropriateness of these strategies and encourage other approaches.
\end{abstract}

\section{Introduction}

Facing stressors in our life is part of the humanitarian formula. It is a common challenge we encounter at some stages of our lives. Stressors are not always perceived negatively. In fact, we need some challenges that will be accompanied by stressors to keep us motivated and push us to try harder. ${ }^{1}$ However, some stressors can cause negative psychological implications. The "ability to maintain positive well-being (not merely lack of psychopathology) despite exposure to stressors is defined as resilience". ${ }^{2}$ Individuals' resilience is an internal characteristic that distinguishes individuals' reactions to stressors; On the other hand, strategies that one applies to survive and manage stressors are called coping strategies. Coping is defined as "the decision of which behaviors to utilize to handle the event". ${ }^{1}$ It can be seen as an "interaction between the person's internal resources and external environmental demands". ${ }^{1}$

The novel outbreak of coronavirus disease 2019 (COVID-19) is stressful. Fear and anxiety of infection and transmission can be overwhelming and might cause psychological disturbance..$^{3-7}$ Like other pandemics, survivors might face stigmatization and societal seclusion even in their own society. ${ }^{8}$ Even those not being affected will suffer from the curfew or quarantine measurements applied in the affected area. Such enforced measures impose people's lives, attack their freedom, and (in many cases) separate them from their loved ones. ${ }^{9}$

Recovering from an epidemic is not given or straight forward. In fact, an epidemic's psychological effect can begin as soon as the epidemic itself is initiated ${ }^{7}$ and recovery from the aftermath might take up to a decade. ${ }^{8}$ To recover from a natural disaster, people use various coping strategies. However, not only some coping strategies do not succeed in helping to deal with the situation, some might be deadly harmful. ${ }^{10}$

Outbreaks of infectious diseases and the actions taken to contain it such as curfew and quarantine measures are considered large-scale stressors and have psychological implications, especially on students. ${ }^{11}$ Emotional instability, panic and anxiety are among the other symptoms of psychological disturbance. Because outbreaks of infectious diseases occur rarely, their psychological influence is under investigated. ${ }^{2}$ Nevertheless, such a stressor is "a unique opportunity to study individuals' psychological adjustment under stress". ${ }^{2}$ As for the recent unexpected COVID-19 pandemic, researchers are still working to provide the right treatment and vaccinations, hence, minimum research has been conducted on the coping strategies used to survive this pandemic.

Significance for public health

Students, being part of the community, are experiencing the social and psychological impacts of the novel COVID-19 pandemic. In addition to coping with the new methods of learning and assessments, the fear of them or their loved ones contracting the disease and the unusual quarantine circumstances could lead to social and psychological anxiety. Such anxiety can affect their well-being and threatened the health status of their families. Thus, this study aims to address their concerns and learn about the strategic interventions that need to be put in place to minimize any adverse or long-term effects of the pandemic in students' lives. The research outcome brings added value for universities to adopt and incorporate feasible and fair approaches in handling students' socio-psychological preparedness. Moreover, the findings enlighten the public on the appropriate coping strategies and the suitable adaptability skills that can be emphasized to pass through such a pandemic with a minimum health effect. 
Especially because COVID-19 is an unprecedented incident in Saudi Arabia, people apply coping strategies mostly based on their own knowledge and intuitions. University students, as part of this society, face such unexpected situations with some strategies. Hence, it is essential to learn about the coping strategies applied during COVID-19 in Saudi Arabia. The results of this study will inform the society on any needed intervention for the current epidemics and the future advice that might be shared with the public. Due to students' anxiety about uncertainty in the academic year, and uncertainty in their assessments, this paper aims to determine the coping strategies used by college and university students during the COVID-19 pandemic.

\section{Related literature}

Humans react differently when it comes to unanticipated disasters. There are several factors that influence the amount of damage an individual might experience as a result of a disaster. It is probably convincing to argue that the prior mental and psychological status of an individual is an important factor that will contribute to the ability to cope with the pandemic or the actions related to it, such as quarantine measures. ${ }^{3,12}$ In fact, it is a multidimensional system ${ }^{13}$ that depends on several factors, including the person's personality, environment, sex, culture, and the stressor itself. ${ }^{14}$ At one end of this spectrum of strategies is denial. Avoiding or denial is one passive coping strategy. Not only does the passive coping approach not improve the situation, it might also lead to serious mental illness. ${ }^{7}$ Moreover, previous research shows that young adolescents, especially, might use dangerous strategies, such as excessive use of alcohol ${ }^{15}$ and marijuana or even cutting themselves and attempting suicide, to gain attention or relieve emotional distress. ${ }^{10}$

At the other end is the active approach, where a person faces the problem and tries to deal with it directly. In that case, a person might apply problem-solving skills to deal with the stressor or seek support from family and friends to facilitate coping and recovery. ${ }^{14}$ During quarantine, the creation of productive time ${ }^{15}$ and the intensive use of exercises or meditation methods are active coping strategies. Tai chi practice, for example, was one coping approach used by survivors of SARS in Hong Kong. ${ }^{8}$ In addition, acceptance and self-regulation of one's emotions are other active coping approaches that will protect an individual from being severely affected by the stressor or the disaster. ${ }^{14,16}$ Interestingly, talking about the issue or even joking about it could help. ${ }^{15}$ In sum, the avoidant approach has been associated with negative psychological impacts whereas the active approach was found to result in minimum psychological disturbance. ${ }^{7,17}$ This is relatively convincing, as the passive approach tends not to change the situation. ${ }^{2}$ To the contrary, the active approach seeks to understand the problem, address it, and discover a solution.

\section{COVID-19 in the Kingdom of Saudi Arabia}

The first case of COVID-19 in the Kingdom of Saudi Arabia (KSA) was reported on March 2, 2020. However, the number of cases increased dramatically to reach 100,000 by June $2020 .^{18}$ Accordingly, beginning March 8, several unprecedented decisions have been made to control the virus. For example, all schools and higher education institutions were closed and a virtual mode of education was imposed for the remainder of the academic year.

\section{Coping strategies in KSA}

COVID-19 has changed the life of every Saudi. Social life is one essential factor for families in KSA. A typical family consists of 5-6 people, and a family gathering with extended family members every week is a traditional event. KSA is also known for its massive religious gatherings, such as Umra and visitations to the Prophet's mosque. These are held at different times throughout the year but are more active during the holy month of Ramadan-most recently held in May 2020, the peak of the pandemic. Moreover, other social, religious, or family gatherings occur just after the holy month and during Eid Alfitr. Hence, the fact that COVID-19 lockdowns took place during such critical times of the year definitely made coping with the situation much harder. ${ }^{19}$

However, KSA has made efforts to help people cope with this unprecedented situation. Some studies suggest that effective mitigation measures must be imposed during the quarantine planning process to reduce the negative psychological effects; these measures include providing the public with information that explains the nature of the risks they are facing and why they were being quarantined, and providing the people who are quarantined with basic needs. ${ }^{3}$ For instance, to reduce fear and anxiety, the Ministry of Health (MOH) in KSA encouraged the public to obtain information only from reliable sources and to avoid rumours. Moreover, the $\mathrm{MOH}$ held several coronavirus follow-up meetings to report accurate information about the disease, the current situation in kingdom, and the preventive measures that must be followed. This is consistent with previous findings that stated that the level of anxiety due to a disaster is associated with the extent to which the people are well-informed and the transparency of information. ${ }^{20}$ Providing adequate access to information has been shown to influence people coping with disasters. ${ }^{12}$

Moreover, permission to leave home or even to travel among cities is granted in emergency or humanitarian situations. People can apply through an announced application (Tawakkalna) for such permissions. Several applications were available to be used for delivery, either for basic requirements, such as grocery shopping, or even to order coffee or ice cream. ${ }^{21,22}$ Such measurements gave people alternatives and helped them apply the quarantine actions satisfactorily. On the other hand, people in KSA applied several coping strategies. The young generation focused their energy on alternative activities. Instead of meeting with friends, they developed new hobbies, such as cooking and gardening. ${ }^{23}$ They even shared this with friends through social media channels. For others, to be proactive and instead of complaining about the situation, they created jokes and sarcastic comments.

\section{Materials and Methods}

This study examined the coping strategies used by university students in KSA to deal with the unprecedented pandemic of COVID-19. An online questionnaire was administered to all students at one private university in the capital city of Riyadh between April 20 and June 6, 2020. Students were informed that their participation was voluntary and their consent was obtained. The study used anonymous data to ensure confidentiality. By June 6, 2020, a total of 400 responses had been received. It is important to mention here that the researchers have obtained ethical approval from the Institutional Review Board (IRB) of the university.

\section{Research instrument}

The instrument was partially self-developed and it consisted of 
three sections. The first section of the questionnaire obtained demographic data, such as age, gender, and field of study. Items about the mode of study during COVID-19 and living conditions were added. In the second section, the researchers used Zung's ${ }^{24}$ Self-rating Anxiety Scale (SAS) as an instrument to examine the anxiety level of the participants. The instrument consists of 20 items, with a 0.70 reliability rate and a 0.60 criterion-related validity rate. ${ }^{24}$ In the 20 -item SAS, each item is scored on a Likert scale of 1 to 4 , coded as: 1 = "Never or very rare," 2 = "Sometimes," 3 $=$ "Often," and $4=$ "Very often or always." For each respondent, the total anxiety score was obtained by adding the responses for the 20 items. The total score ranged from 20 to 80 . The scores were then converted to an Anxiety Index, with values ranging from 25 to 100 . Based on the responses, participants' anxiety levels were classified as "normal" (<45)," "mild to moderate" (45-59), "severe anxiety" (60-74), and "most extreme" (75 and over).

The third section consisted of several items to measure the coping strategies applied by students. Each item was rated on a scale of 1 to 4: 1="never/rarely," 2="sometimes," 3="often," and 4="very often/always." They were divided among four categories: i) Seek social support (4 items), ii) Acceptance (4 items), iii) Mental disengagement (4 items), and iv) Humanitarian (3 items). The first category refers to pursuing help or support from family or friends. ${ }^{25}$ An example would be an item that stated: "During Covid-19 and lockdown, I discuss my feeling with someone". The Acceptance category is when a person adapts and tolerates the unpleasant situation. ${ }^{26}$ For example, a student might agree on the item: "About Covid-19 and lockdown, I accept the reality of the fact that it is happening". On the other hand, Mental Disengagement means that an individual disconnects from the negative situation and directly engage in other activities. ${ }^{27}$ Watching TV or doing indoor sports is one example of a mental disagreement approach. Finally, the Humanitarian coping strategy includes reaching out to others and attempting to helping them. ${ }^{28}$ For example, the student might agree with the statement: "During Covid-19 and lockdown, I pray for those who are infected with COVID-19" (see the Appendix for the full instrument). For each coping category, the mean scores for the respective items were computed, and higher scores implied higher levels of use. It is important to mention here that in the pilot study, the Cronbach's alpha values were a $0.931,0.923,0.683$ and 0.796 for the items in the four categories respectively.

\section{Data analysis}

This research used IBM SPSS version 22 software to analyse the data. Chi-square and ordinal regression procedures were applied to explore the association between demographic variables and coping style. Next, the associations between anxiety level and demographic information with the coping strategy style were tested.

\section{Results}

The purpose of this paper is to identify the strategies that university students in KSA used in coping with anxiety during the COVID-19 pandemic, from March 2020 to June 2020. The sample was selected from Prince Sultan University in Riyadh, the capital city of KSA.

\section{Demographic characteristics}

In this study, 400 responses were received. The demographic characteristics of the respondents are shown in Table 1. Out of the 400 respondents, $75.25 \%$ (301) were females, and $24.75 \%$ (99) were males. Most of the respondents were Saudi, with only $13 \%$ (52) non-Saudi participants. With regard to age, $93.5 \%$ of the respondents were age 19-25 years. One-third of the students were from the College of Business Administration, and around one-sixth each were from the College of Law and the College of Computer and Information Sciences. Most of the students (80\%) were undergraduates, and 20\% were in the Preparatory Year Program (PYP). With regard to accommodation, $89.8 \%$ (359) were living in their family homes. Moreover, it terms of their living arrangement, $94.2 \%$ were staying with their families.

\section{Levels of anxiety}

Based on the Zung scale, among the respondents, $21.5 \%$ (86), $8.8 \%$ (35), and $4.3 \%$ (17) experienced minimal to moderate, marked to severe, and most extreme levels of anxiety, respectively. For further analysis, respondents in the marked to severe anxiety category and the most extreme anxiety category were grouped as severe to extreme levels of anxiety. A summary of the results is shown in Table 2 .

\section{Coping strategies and anxiety}

Four coping strategies_-"Seek social support," "Acceptance," "Mental disengagement," and "Humanitarian"-were tested. The mean scores for the respective items were computed. The descriptive summary for the coping strategies is shown in Table 3. Overall, the usage of all four strategies was moderate. The distributions were fairly normal (skewness $<2$, kurtosis $<7$ ). Overall, the students practiced more acceptance strategies and fewer seekingsocial-support strategies.

Table 1. Demographic characteristics of the respondents.

\begin{tabular}{|c|c|c|}
\hline Variable & Frequency & Percentage \\
\hline $\begin{array}{l}\text { Gender } \\
\quad \text { Female } \\
\text { Male }\end{array}$ & $\begin{array}{c}301 \\
99\end{array}$ & $\begin{array}{l}75.2 \\
24.8\end{array}$ \\
\hline $\begin{array}{l}\text { Age } \\
\quad \leq 18 \text { years } \\
19-25 \text { years } \\
\geq 26\end{array}$ & $\begin{array}{c}15 \\
374 \\
11\end{array}$ & $\begin{array}{c}3.8 \\
93.5 \\
2.8\end{array}$ \\
\hline $\begin{array}{l}\text { College } \\
\text { Business Administration } \\
\text { Computing \& IS } \\
\text { Engineering } \\
\text { Humanities } \\
\text { Law } \\
\text { Preparatory Year Program }\end{array}$ & $\begin{array}{l}131 \\
73 \\
65 \\
16 \\
69 \\
46\end{array}$ & $\begin{array}{c}32.8 \\
18.2 \\
16.2 \\
4.0 \\
17.2 \\
11.5\end{array}$ \\
\hline $\begin{array}{l}\text { Level of study } \\
\text { Preparatory Year Program } \\
\text { Undergraduate }\end{array}$ & $\begin{array}{c}79 \\
321\end{array}$ & $\begin{array}{l}19.8 \\
80.2\end{array}$ \\
\hline $\begin{array}{l}\text { Year of study } \\
\text { Year } 1 \\
\text { Year } 2 \\
\text { Year } 3 \\
\text { Year } 4 \\
\text { Year } 5 \text { and above }\end{array}$ & $\begin{array}{l}127 \\
72 \\
74 \\
72 \\
55\end{array}$ & $\begin{array}{c}31.8 \\
18.0 \\
18.5 \% \\
18.0 \\
13.8\end{array}$ \\
\hline $\begin{array}{l}\text { Current accommodation } \\
\text { Family home } \\
\text { Rented premises }\end{array}$ & $\begin{array}{c}359 \\
41\end{array}$ & $\begin{array}{l}89.8 \\
10.2\end{array}$ \\
\hline $\begin{array}{l}\text { Currently staying with } \\
\text { Family/relatives } \\
\text { Alone }\end{array}$ & $\begin{array}{c}377 \\
23\end{array}$ & $\begin{array}{c}94.2 \\
5.8\end{array}$ \\
\hline
\end{tabular}




\section{Coping strategies used, by students' demography}

Differences in the usage of the four coping strategies were tested using the Multivariate Analysis of Variance (MANOVA) procedure. The results are provided in Table 4 . There were significant differences in means in gender, college, level of study, and current accommodations. Generally, females used the seek-social-support coping strategy more frequently than the males, and those from the College of Humanities used this strategy more than those from the College of Law.

The usage of the mental-disengagement coping strategy was higher among the PYP students compared to the undergraduates. The students who stayed in family homes used the humanitarian coping strategy more frequently than those who stayed at rented premises.

The associations between coping strategies used and level of anxiety were tested using Analysis of Variance (ANOVA) procedures. In the analyses, the variances were similar. The results are shown in Table 5. Out of the four strategies, only "Acceptance" was significantly associated with level of anxiety. The usage of the "Acceptance" coping strategy was higher in the "Normal" anxiety group compared to the "Severe to extreme" anxiety group.

\section{Open-ended responses analysis}

The qualitative data support the statistical results presented above. Only $35 \%$ of the respondents were classified as anxious, and only $13 \%$ were grouped in the "Severe to extreme" level. So, many students were just fine. This is consistent with students' comments: "Sure, life isn't as amazing as before, but we're appreciating every little thing we took for granted." Gender differences showed that females are more likely to seek social support. This is a natural instinct, as males might feel that they do not want to seek help from anyone. This justification is supported by the following comment: "I am a man and I can live with that." Moreover, seeking social support is a way of venting and sharing. Participants felt better just because they were given a chance to reflect about their feeing by completing this survey, which is apparent from the follow-

Table 2. Anxiety levels based on Zung's Classification

\begin{tabular}{|c|c|c|c|c|c|}
\hline Anxiety & Frequency & Percentage & Anxiety & Frequency & Percentage \\
\hline Normal & 262 & 65.5 & Normal & 262 & 65.5 \\
\hline Minimal to moderate & 86 & 21.5 & Minimal to moderate & 86 & 21.5 \\
\hline Marked to severe & 35 & 8.8 & Severe to extreme & 52 & 13.0 \\
\hline Most extreme & 17 & 4.3 & & & \\
\hline
\end{tabular}

Table 3. Descriptive statistics for coping strategies.

\begin{tabular}{lcccc} 
Coping strategy & Mean $\pm \mathrm{S}$ & Median & Skewness & Kurtosis \\
Seek social support & $2.12 \pm 0.87$ & 2.00 & 0.519 & 0.628 \\
Avoidance & $2.94 \pm 0.81$ & 3.00 & 0.385 & 0.645 \\
\hline Mental disengagement & $2.54 \pm 0.63$ & 2.50 & 0.286 & 0.031 \\
Humanitarian & $2.53 \pm 0.80$ & 2.33 & 0.158 & 0.757 \\
\hline
\end{tabular}

Table 4. Results from Multivariate analysis of variance (MANOVA).

\begin{tabular}{|c|c|c|c|c|}
\hline Variable & Seek social support & Avoidance & Mental disengagement & Humanitarian \\
\hline $\begin{array}{l}\text { Gender } \\
\text { Female } \\
\text { Male }\end{array}$ & $\begin{array}{c}0.003 \\
218 \pm 0.86^{\mathrm{a}} \\
1.91 \pm 0.86^{\mathrm{a}}\end{array}$ & $\begin{array}{c}0.976 \\
2.94 \pm 0.79 \\
2.392 \pm 0.85\end{array}$ & $\begin{array}{c}0.398 \\
2.53 \pm 0.64 \\
2.57 \pm 0.58\end{array}$ & $\begin{array}{c}0.148 \\
2.57 \pm 0.79 \\
2.42 \pm 0.83\end{array}$ \\
\hline $\begin{array}{l}\text { College } \\
\text { Business Administration } \\
\text { Computing \& IS } \\
\text { Engineering } \\
\text { Humanities } \\
\text { Law } \\
\text { PYP }\end{array}$ & $\begin{array}{c}0.919 \\
2.13 \pm 0.88 \\
2.33 \pm 0.97 \\
2.07 \pm 0.81 \\
2.44 \pm 0.75^{\mathrm{a}} \\
1.88 \pm 0.82^{\mathrm{a}} \\
2.03 \pm 0.87\end{array}$ & $\begin{array}{c}0.646 \\
2.97 \pm 0.79 \\
2.90 \pm 0.76 \\
3.00 \pm 0.76 \\
3.01 \pm 0.54 \\
2.82 \pm 0.89 \\
2.97 \pm 0.82\end{array}$ & $\begin{array}{c}0.749 \\
2.53 \pm 0.65 \\
2.57 \pm 0.55 \\
2.38 \pm 0.57 \\
2.44 \pm 0.55 \\
2.56 \pm 0.71 \\
2.73 \pm 0.62\end{array}$ & $\begin{array}{c}0.109 \\
2.68 \pm 0.81 \\
2.46 \pm 0.83 \\
2.45 \pm 0.63 \\
2.50 \pm 0.74 \\
2.39 \pm 0.86 \\
2.57 \pm 0.86\end{array}$ \\
\hline $\begin{array}{l}\text { Level of study } \\
\text { PYP } \\
\text { Undergraduate }\end{array}$ & $\begin{array}{c}0.745 \\
2.12 \pm 0.752 \\
2.12 \pm 0.89\end{array}$ & $\begin{array}{c}0.391 \\
3.01 \pm 0.79 \\
2.92 \pm 0.81\end{array}$ & $\begin{array}{c}0.048 \\
2.72 \pm 0.58^{\mathrm{a}} \\
2.49 \pm 0.63^{\mathrm{a}}\end{array}$ & $\begin{array}{c}0.333 \\
2.61 \pm 0.79 \\
2.51 \pm 0.80\end{array}$ \\
\hline $\begin{array}{l}\text { Current accommodation } \\
\text { Family home } \\
\text { Rented premises }\end{array}$ & $\begin{array}{c}0.631 \\
2.11 \pm 0.87 \\
2.15 \pm 0.84\end{array}$ & $\begin{array}{c}0.145 \\
2.95 \pm 0.80 \\
2.79 \pm 0.0 .84\end{array}$ & $\begin{array}{c}0.134 \\
2.56 \pm 0.63 \\
2.35 \pm 0.57\end{array}$ & $\begin{array}{c}0.021 \\
2.56 \pm 0.81^{\mathrm{a}} \\
2.24 \pm 0.69^{\mathrm{a}}\end{array}$ \\
\hline
\end{tabular}

The numbers in bold are p-values for the difference in the strategy used by the respective demographic characteristic. ${ }^{a}$ pairwise differences. 
ing comments:

"I love this survey a lot; it made me know myself more!!"

"Thank you for doing this."

"This was a really good survey and it has helped me to feel there is someone who feels for me and cares about me."

"Thank you for being concerned and caring; we really appreciate it."

Mental disengagement is also clear from some responses:

"Honestly, because of the free time I have because of COVID19, I started learning a

new language and improving my academic skills more than I did at Uni."

\section{Discussion}

Natural disasters, such as pandemics, are outbreaks unanticipated by many people in society. Individuals have experienced fears, anxiety, and depression during the pandemic due to changes to their daily activities, financial security, and their loved ones' well-being. ${ }^{29}$ Previous studies indicate the use of different coping methods in reducing anxiety and stress. ${ }^{29,30}$

This paper examined the coping strategies that university students in KSA have practiced to handle anxiety during the COVID19 outbreak. The results indicate that, among this young generation, only a small percentage $(13 \%)$ of the responding students experienced some severe to extreme level of anxiety. Thus, many students got along well, and the association of the acceptance strategy and the normal level of anxiety is convincing. This does not coincide with previous studies that have reported on the effects of COVID-19. ${ }^{31}$ The authors argued that younger generations are more vulnerable and less resilient to disasters. However, the fact that this research focused on a young generation (university students) who have no experience or knowledge about what to expect from such a pandemic, and the fact that this research occurred at the early stage of the pandemic, could explain this result.

Moreover, the descriptive statistics showed that students used all types of coping strategies. This suggests that their mental health and natural intuition guided them to the strategy that is best for them to use. However, this usage was related to some demographic data. The observation that females seek social support more than males is convincing. In fact, previous studies revealed that females react differently to disaster than do males. ${ }^{12,32-34}$ Moreover, Cvetković et al. ${ }^{35}$ argued that females' caring social attitudes make them more willing to reach out to others to help or to seek help during disasters.

The selection of the coping strategies can be attributed to nature or convenience, or even to luck or coincidence. The lack of experience and the limited research funding and knowledge among the Saudi community increased the self-selection process. This is a significant finding and, in fact, dangerous. Previous research has argued about the importance of identifying coping strategies and encouraging the public to apply them. ${ }^{31,36}$ Then, these suggested coping strategies must be translated into doable protocols to be used in the future by students. For example, Columbia University announced a list of coping strategies to be used by students to deal with the pandemic. ${ }^{37}$

\section{Limitations}

The study focused on students in KSA from one private university. This decision was made to avoid time constraints in obtaining IRB approval from various higher education institutions. The respondents are mostly Saudi students. Hence, the findings should not be generalized to the overall student population.

\section{Implications and conclusions}

The world has been attacked by an unprecedented pandemic, COVID-19, and this has influenced university students in KSA. The ability to survive this catastrophic event depends to a great extent on their reaction to it. The psychological impact of the pandemic, or any harsh decisions to contain it, on students cannot be ignored. The well-being of individuals is affected by anxiety, depression, and other psychological responses and can continue even after the outbreak. ${ }^{29,38}$ To ease such impacts, certain strategies can be adopted to cope. However, ideal and safe coping strategies must be identified and encouraged by students to face this pandemic and other challenges in the future. Prioritizing research on the mental health, anxiety, and coping strategies of students, along with psychological effects, needs to occur on an urgent basis. This is consistent with the previous findings that argued that identifying coping strategies is essential, ${ }^{31,36}$ and may help to ensure sustainable educational development in the world.

Moreover, the findings of this research inform the Saudi community on what strategies were used, so far, to cope with the pan-

Table 5. Anxiety level and coping strategies.

\begin{tabular}{|c|c|c|c|c|}
\hline Coping strategy & Anxiety level & Mean $\pm \mathrm{S}$ & F & $\mathbf{P}$ \\
\hline Seek social support & $\begin{array}{l}\text { Normal } \\
\text { Minimal to Moderate } \\
\text { Severe to Extreme }\end{array}$ & $\begin{array}{l}2.06 \pm 0.88 \\
2.17 \pm 0.82 \\
2.31 \pm 0.86\end{array}$ & 2.072 & 0.127 \\
\hline Avoidance & $\begin{array}{l}\text { Normal } \\
\text { Minimal to Moderate } \\
\text { Severe to Extreme }\end{array}$ & $\begin{array}{l}3.02 \pm 0.81^{\mathrm{a}} \\
2.82 \pm 0.81 \\
2.72 \pm 7.49^{\mathrm{a}}\end{array}$ & 4.121 & 0.017 \\
\hline Mental disengagement & $\begin{array}{l}\text { Normal } \\
\text { Minimal to Moderate } \\
\text { Severe to Extreme }\end{array}$ & $\begin{array}{l}2.57 \pm 0.62 \\
2.55 \pm 0.65 \\
2.37 \pm 0.64\end{array}$ & 2.306 & 0.101 \\
\hline Humanitarian & $\begin{array}{l}\text { Normal } \\
\text { Minimal to Moderate } \\
\text { Severe to Extreme }\end{array}$ & $\begin{array}{l}2.55 \pm 0.82 \\
2.60 \pm 0.75 \\
2.32 \pm 0.77\end{array}$ & 2.226 & 0.109 \\
\hline
\end{tabular}

${ }^{a}$ pairwise differences 
demic. However, future research must focus on the validity of these strategies and the possibility of encouraging other approaches. Moreover, using in-depth data collection strategies, such as interviews or focus groups, in future research can help explain why students adopted one strategy more than others.

\author{
Correspondence: Heba Bakr Khoshaim, Deanship of Educational \\ Services, Prince Sultan University, Riyadh, Saudi Arabia. \\ Tel.: +966.559939984 \\ E-mail: hkhoshaim@psu.edu.sa
}

Key words: Kingdom of Saudi Arabia; coping strategies; university students; anxiety; COVID-19.

Acknowledgement: The researchers would like to acknowledge Prince Sultan University for its support for this project through PSU COVID-19 Emergency Research Program (Grant ID: COVID-19CBA-2020-39).

Contributions: HBK, wrote the first draft of the manuscript and revised accordingly; AA, collected the data and wrote the discussion and conclusion; $\mathrm{KC}$, designed and analyzed the data; MN, SS, KK, conceptualized and critically reviewed the paper; GMB, SFAH, reviewed the questionnaire and the analysis. All authors reviewed and approved the final version of the manuscript before submitting.

Conflict of interest: One of the authors is the guest editor of the special issue. The other authors have no conflict of interest to declare.

Funding: This study was financially supported by Prince Sultan University.

Ethical approval: The researchers have obtained the ethical approval from the Institutional Review Board (IRB) of the university.

Availability of data and material: Data are available upon request.

Received for publication: 13 August 2020.

Accepted for publication: 5 December 2020.

oCopyright: the Author(s), 2020

Licensee PAGEPress, Italy

Journal of Public Health Research 2020; 9(s1)1898

doi:10.4081/jphr.2020.1898

This work is licensed under a Creative Commons Attribution NonCommercial 4.0 License (CC BY-NC 4.0).

\section{References}

1. Matthieu MM, Ivanoff A. Using stress, appraisal, and coping theories in clinical practice: Assessments of coping strategies after disasters. Brief Treat Cris Interv 2006;6:337-48. doi: 10.1093/brief-treatment/mhl009.

2. Main A, Zhou Q, Ma Y, et al. Relations of SARS-related stressors and coping to Chinese college students' psychological adjustment during the 2003 Beijing SARS pandemic. J Couns Psy 2011;58:410-23. doi: 10.1037/a0023632.

3. Brooks SK, Webster RK, Smith LE, et al. The psychological impact of quarantine and how to reduce it: Rapid review of the evidence. The Lancet 2020;395:912-20. doi: 10.1016/s01406736(20)30460-8.

4. Cao W, Fang Z, Hou G, et al. The psychological impact of the
COVID-19 epidemic on college students in China. Psy Res 2020;287:112934. doi: 10.1016/j.psychres.2020.112934.

5. Lai J, Ma S, Wang Y, et al. Factors associated with mental health outcomes among health care workers exposed to Coronavirus Disease 2019. JAMA Net Open 2019;3:e203976. doi: 10.1001/jamanetworkopen.2020.3976.

6. Wang C, Pan R, Wan X, et al. Immediate psychological responses and associated factors during the initial stage of the 2019 coronavirus disease (COVID-19) pandemic among the general population in China. Intern $\mathrm{J}$ Enviro Resea Pub Heal 2020;17:1729. doi: 10.3390/ijerph17051729.

7. Wang H, Xia Q, Xiong Z, et al. The psychological distress and coping styles in the early stages of the 2019 coronavirus disease (COVID-19) pandemic in the general mainland Chinese population: A web-based survey. PLoS ONE 2020;15:e0233410. doi: 10.1371/journal.pone.0233410.

8. Siu JY-M. Coping with future pandemics: Tai chi practice as an overcoming strategy used by survivors of severe acute respiratory syndrome (SARS) in post-SARS Hong Kong. Heal Expec 2014; 19:762-72. doi: 10.1111/hex.12270

9. Ries NM. Chapter 3: The 2003 SARS outbreak in Canada: Legal and ethical lessons about the use of quarantine. In: Balint J, Philpott S, Baker R, Strosberg M (eds). Ethics and Pandemics Advances in Bioethics. Bingley, UK: Emerald Group Publishing Limited; 2006. p. 43-67. doi: 10.1016/ s1479-3709(06)09003-0.

10. Selekman MD, Helping self-harming students. Educ Lead 2009;67:48-53. Available form: http://www.ascd.org/publications/educational_leadership/dec09/vol67/num04/Helping_Sel f-Harming_Students.aspx.

11. Qiu J, Shen B, Zhao M, et al. A nationwide survey of psychological distress among Chinese people in the COVID-19 pandemic: Implications and policy recommendations. Gen Psy 2020;33:e100213. doi: 10.1136/gpsych-2020-100213

12. Neumayer E, Plümper T. The gendered nature of natural disasters: The impact of catastrophic events on the gender gap in life expectancy, 1981-2002. J Ann Asso Ameri Geographers 2008;97:551-66. doi: 10.1111/j.1467-8306.2007.00563.x.

13. Skinner EA, Edge K, Altman J, Sherwood H. Searching for the structure of coping: A review and critique of category systems for classifying ways of coping. Psy Bull 2003;129:216-69. doi: 10.1037/0033-2909.129.2.216.

14. Polizzi C, Lynn SJ, Perry A. Stress and coping in the time of COVID-19: Pathways to resilience and recovery. Clin Neuropsychiatry 2020;17:59-62. doi: 10.36131/CN20200204.

15. Berman R. How do people cope with the pandemic? Survey reveals worrying trends. Med News Tod 2020. Available from: https://www.medicalnewstoday.com/articles/how-do-peoplecope-with-the-pandemic-survey-reveals-worrying-trends.

16. Makwana N. Disaster and its impact on mental health: A narrative review. J Family Med Prim Care 2019;8:3090-5.

17. Compas BE, Connor-Smith JK, Saltzman H, Thomsen AH, Wadsworth ME. Coping with stress during childhood and adolescence: Problems, progress, and potential in theory and research. Psy Bull 2001;127:87-127. doi: 10.1037/00332909.127.1.87

18. Ministry of Health. MOH: 3,045 New COVID-19 Cases Reported, Recoveries Surpass 72,000. Saudi Arabia Ministry of Health. 2020. Available from: https://www.moh.gov.sa/ en/Ministry/MediaCenter/News/Pages/News-2020-06-07005.aspx.

19. Lee E, Lee H. Disaster awareness and coping: Impact on stress, anxiety, and depression. Persp in Psychiatric Care 2019;55:311-8. 
20. Khalid T. Coronavirus: How to use Saudi Arabia's 'Tawakkalna' app to get movement permits. English Alarabiya 2020 May 26. Available from: https://english.alarabiya.net/en/ coronavirus/2020/05/26/Coronavirus-How-to-use-SaudiArabia-s-Tawakkalna-app-to-get-movement-permits.

21. Arab News. Delivery app reps cleared to operate in Saudi Arabia at all hours. Arab News. 2020 Apr 10. Available from: https://www.arabnews.com/node/1656286/saudi-arabia.

22. Bashraheel A. Saudis adopt new hobbies to get through quarantine. Arab News. 2020 May 29. Available from: https://www.arabnews.com/node/1681456/saudi-arabia.

23. Zung WWK. A rating instrument for anxiety disorders. Psychosomatic 1997; 12:371-9.

24. Dumont M, Provost M. Resilience in adolescents: Protective role of social support, coping strategies, self-esteem, and social activities on experience of stress and depression. J Youth Adolesc 1999;28:343-63.

25. Nakamura YM, Orth U. Acceptance as a coping reaction: Adaptive or not? Swiss J Psychol 2005;64:281-92.

26. Traeger L. Distraction (coping strategy). Encyclopedia of Behavioral Medicine. 2013. doi: 10.1007/978-1-4419-1005-9.

27. Schwartz CE, Sendor RM. Helping others helps oneself: Response shift effects in peer support. Soc Sci Med 1999;48:1563-75. doi: 10.1016/s0277-9536(99)00049-0.

28. Chew Q, Wei K, Vasoo S, et al. Narrative synthesis of psychological and coping responses towards emerging infectious disease outbreaks in the general population: Practical considerations for the COVID-19 pandemic. Singapore Med J 2020;16:350-356. doi: 10.11622/smedj.2020046.

29. Baumstarck K, Alessandrini M, Hamidou Z, et al. Assessment of coping: A new French four-factor structure of the brief COPE inventory. Hea Qual Life Out 2017;15. doi: 10.1186/s12955-016-0581-9.

30. Ahmed MZ, Ahmed O, Aibao Z, et al. Pandemic of COVID-19 in China and associated psychological problems. Asian J Psychiatr 2020;51:102092. doi: 10.1016/j.ajp.2020.102092.

31. Chaplin TM. Gender and emotion expression: A developmental contextual perspective. Emot Rev 2015;7:14-21. doi: $10.1177 / 1754073914544408$.

32. Kring AM, Gordon AH. Sex differences in emotion: Expression, experience, and physiology. J Pers Soci Psychol 1998;74:686-703. doi: 10.1037/0022-3514.74.3.686.

33. World Health Organization. Gender and Health in Disasters. Geneva: Department of Gender and Women's Health, World Health Organization. 2020. Available from: https://www.who. int/gender/other_health/genderdisasters.pdf.

34. Cvetković VM, Roder G, Öcal A, et al. The role of gender in preparedness and response behaviors towards flood risk in Serbia. Intern J Environ Res Pub Heal 2018;15:1-21. doi: 10.3390/ijerph15122761.

35. Wong TW, Gao Y, Tam WWS. Anxiety among university students during the SARS pandemic in Hong Kong. Stress Health 2007;23:31-35. doi: 10.1002/smi.1116.

36. Columbia University (Irving Medical Center). Coping with the stress of a Pandemic: A mental health guide for CUIMC students. Columbia University, 2020. Available from: https://www.cumc.columbia.edu/student-health/coping-stresspandemic-mental-health-guide-cuimc-students.

37. Lau AL, Chi I, Cummins RA, et al. The SARS (Severe Acute Respiratory Syndrome) pandemic in Hong Kong: Effects on the subjective wellbeing of elderly and younger people. Aging Men Health 2008;12:746-760. doi: 10.1080/1360786080 2380607 